\title{
Eosinophil degranulation status in allergic rhinitis: observations before and during seasonal allergen exposure
}

\author{
C.A. Ahlstrom-Emanuelsson*, L. Greiff*, M. Andersson*, C.G.A. Persson*, J.S. Erjefält"
}

\begin{abstract}
Eosinophil degranulation status in allergic rhinitis: observations before and during seasonal allergen exposure. C.A. Ahlstrom-Emanuelsson, L. Greiff, M. Andersson, C.G.A. Persson, J.S. Erjefält. (C) ERS Journals Ltd 2004.

ABSTRACT: Despite the fact that extensive degranulation is a likely prerequisite for a pathogenic role of eosinophils, little is known about the degranulation status of these cells in eosinophilic conditions. The present study of the ultrastructure of tissue eosinophils explores eosinophil degranulation in allergic rhinitis before and during seasonal allergen exposure.

A total of 23 patients scored symptoms q.d., prior to and during the pollen season. The numbers of mucosal eosinophils and their degranulation status were determined in nasal biopsies. Furthermore, nasal lavage fluid levels of eosinophil cationic protein (ECP) and $\alpha_{2}$-macroglobulin were assessed as indices of eosinophil activity and plasma exudation, respectively.

Seasonal allergen exposure was associated with increased nasal symptoms, increased lavage fluid levels of ECP and $\alpha_{2}$-macroglobulin, and increased numbers of tissue esinophils. In the tissue, transmission electron microscopy revealed a moderate piecemeal degranulation already prior to the season (mean \pm SD $37 \pm 2.7 \%$ altered granules). Seasonal allergen exposure increased this degranulation $(87 \pm 1.8 \%)$, and produced local areas with extensive deposition of granule proteins. The degree of eosinophil degranulation correlated with levels of ECP in lavage fluids obtained at histamine challenge.

In conclusion, this study demonstrated that the nasal mucosa in allergic rhinitis features moderately degranulated eosinophils already at nonsymptomatic baseline conditions. In association with the development of symptomatic seasonal allergic rhinitis, the tissue deposition of eosinophil granule proteins is dramatically elevated through increased eosinophil numbers, together with markedly augmented degranulation of individual cells.

Eur Respir J 2004; 24: 750-757.
\end{abstract}

Depts of *Otorhinolaryngology, Head and Neck Surgery, ${ }^{\#}$ Clinical Pharmacology, and Physiological Sciences, Lund University Hospital, Lund, Sweden.

Correspondence: J.S. Erjefält

Dept of Physiological Sciences

BMC F10

Lund University Hospital

22184 Lund

Sweden

Fax: 46462223232

E-mail: jonas.erjefalt@mphy.lu.se

Keywords: Airway tissue

allergy

eosinophil degranulation

Received: December 32003

Accepted after revision: July 52004

The present study was supported by The Swedish Research Council, The Skåne County Council, The Crafoord Foundation, The Asthma \& Allergy Foundation, The Swedish Medical Association, and The Swedish Otolaryngological Association.
Tissue accumulation of eosinophil granulocytes is a characteristic feature of allergic diseases $[1,2]$. For decades, eosinophils have been thought to exert major pathogenic roles in allergic disorders due to their capacity to release highly cytotoxic granule proteins [3, 4]. However, results from clinical trials in asthma involving anti-interleukin (IL)-5 neutralising antibodies $[5,6]$, a therapeutic approach directly aimed at the eosinophil component of this disease, have questioned this view during the last few years [7].

A basic prerequisite for an active pathogenic role of the eosinophil would be that it degranulates in diseased tissues. It is, therefore, of interest that the occurrence of degranulated eosinophils may vary greatly between different diseases [8]. Thus, in the search for pathogenic roles of the eosinophil, it may be helpful to focus particularly on conditions where the tissue eosinophils are highly degranulated. Preliminary results already suggest that eosinophils, occurring in the target tissue during active seasonal allergic rhinitis, may exhibit more pronounced degranulation than in many other common diseases characterised by tissue eosinophilia, e.g. inflammatory bowel disease and asthma [8, 9]. However, as yet, little is known about the dynamics of eosinophil degranulation in allergic rhinitis, especially when the disease progresses from a nonsymptomatic baseline situation into an active symptomatic condition.

The present study has explored the possibility that the development of seasonal allergic rhinitis is associated with markedly increased occurrence of highly degranulated eosinophils in the nasal mucosa. Another goal was to establish the baseline degranulation status in nonsymptomatic patients. Thus, a transmission electron microscopic (TEM) detailed analysis was employed to assess the level of eosinophil degranulation in allergic rhinitis before and during seasonal allergen exposure $[9,10]$. Also, the occurrence of eosinophil cationic protein (ECP) in nasal tissues and lavage fluids was determined.

\section{Materials and methods}

\section{Study design}

Nasal biopsies and saline lavages (with and without histamine) were obtained from patients with strictly seasonal allergic rhinitis before and late into the birch pollen season. The biopsies before the pollen season were obtained on 
March 18, 2000 and those during the pollen season on May 9, 2000. Nasal lavages were performed on the same dates, as well as on April 7, and the May 2, 2000. The numbers of eosinophils in the airway mucosa were determined. Also, the eosinophil degranulation status was assessed using ultrastructural TEM identification of granule changes and immunohistochemical identification of extracellular ECP. Furthermore, nasal lavage fluid levels of ECP and $\alpha_{2-}$ macroglobulin were measured as indices of eosinophil activity and plasma exudation, respectively.

\section{Patients}

A total of 23 patients with seasonal allergic rhinitis were recruited to the study (mean age $28 \mathrm{yrs}$, range $21-46 \mathrm{yrs}$ ). Inclusion criteria were a history of strictly seasonal allergic rhinitis for $\geqslant 2$ yrs and a positive skin prick test to birch pollen allergen. Exclusion criteria were a history of chronic nasal disease (including perennial allergic rhinitis), a history of asthma, a positive skin prick test to perennial allergens and ongoing drug treatment. The study was approved by the local ethics committee and informed consent was obtained.

\section{Symptoms}

Symptoms were recorded q.d. during the study period using diary cards. The recorded symptoms, i.e. rhinorrhoea, nasal blockage and sneezing, were thus scored on a four-graded scale: grade 0 , none; grade 1, mild; grade 2, moderate; and grade 3 , severe symptoms. For each day, a total symptom score was calculated.

\section{Nasal lavages}

A nasal pool device was used for saline lavages and for concomitant histamine challenge and lavages of the nasal mucosa. The latter was employed to produce acute plasma exudation in order to study the possibility that histamineinduced luminal entry of plasma would rinse the tissue and enrich the lavage fluid samples with ECP $[11,12]$. The nasal pool device is a compressible plastic container equipped with a nasal adapter. The adapter is inserted into one of the nostrils, and the container is compressed while the patient is leaning forward in a $60^{\circ}$ flexed-neck position. Thus, the nasal pool fluid is instilled in to one of the nasal cavities, and maintained in contact with a large area of the mucosal surface for a determined period of time. When the pressure on the device is released, the fluid returns into the container. In the present study, the volume of the nasal pool fluid was $15 \mathrm{~mL}$. Nasal lavages with and without histamine were carried out before, and on three occasions, during the pollen season. On each occasion, a 10-min saline lavage was performed first, followed immediately by two 30 -s saline rinsing lavages to remove any additional luminal surface material. After a period of $10 \mathrm{~min}$, a combined 10-min histamine challenge $\left(0.4 \mathrm{mg} \cdot \mathrm{mL}^{-1}\right)$ and lavage was carried out. The nasal lavages were carried out in the morning during laboratory visits. The lavage fluids were centrifuged $\left(325 \times g, 10 \mathrm{~min}, 4^{\circ} \mathrm{C}\right)$ and samples were obtained from the supernatant and frozen $\left(-20^{\circ} \mathrm{C}\right)$, awaiting analysis of ECP and $\alpha_{2}$-macroglobulin.

\section{Nasal biopsies}

Nasal biopsies were obtained before and late into the pollen season. Topical anaesthesia was applied using a solution of tetracain $\left(20 \mathrm{mg} \cdot \mathrm{mL}^{-1}\right)$ and adrenaline $\left(0.1 \mathrm{mg} \cdot \mathrm{mL}^{-1}\right)$, delivered first by a nasal spray device and, thereafter, by a cotton swab. In addition, carbocain $\left(10 \mathrm{mg} \cdot \mathrm{mL}^{-1}\right)$ and adrenalin $\left(5 \mathrm{mg} \cdot \mathrm{mL}^{-1}\right)$ were injected into the inferior nasal turbinate. Two nasal biopsies were taken from the inferior aspects of the turbinate $\sim 0.5 \mathrm{~cm}$ from its anterior margin. Cutting punch forceps $(2 \mathrm{~mm})$, with a drilled-out punch, was used for this purpose. Immediately after excision, one of the biopsies was placed in PBS buffer containing formaldehyde $(3 \%)$ and glutaraldehyde (1\%) and used for electron microscope analysis. The other biopsy was placed in Stefanini's fixative (PBS buffer, pH 7.6, supplemented with 4\% formaldehyde and picric acid) overnight at $4{ }^{\circ} \mathrm{C}$, and later processed for eosinophil peroxidase (EPO) enzyme histochemistry and immunohistochemical identification of ECP.

\section{Lavage fluid levels of $\alpha_{2}$-macroglobulin and eosinophil cationic protein}

The nasal lavage fluid samples were processed by ultrasonication for $15 \mathrm{~min}$. The $\alpha_{2}$-macroglobulin was measured using a radioimmune assay sensitive to $7.8 \mathrm{ng} \cdot \mathrm{mL}^{-1}$ [13]. Rabbit anti-human $\alpha_{2}$-macroglobulin (Dako, Copenhagen, Denmark) was used as anti-serum and human serum (Behringwerke Diagnostica, Marburg, Germany) as standard. Human $\alpha_{2}$-macroglobulin (Cappel-Organon Teknika, Turnhout, Belgium) was iodinated using the lactoperoxidase method. Tracer and standard (or sample) were mixed with anti-serum before adding goat anti-rabbit anti-serum (AstraZeneca, Lund, Sweden). The bound fraction was measured using a gamma counter (Pharmacia Diagnostics, Uppsala, Sweden). The intra- and inter-assay coefficients of variation were $3.8-6.0 \%$ and $3.1-7.2 \%$, respectively. Nasal lavage fluid levels of ECP were measured by a fluoroimmunoassay (Pharmacia Diagnostics), as previously described [14]. The detection level of the assay was $<2 \mathrm{ng} \cdot \mathrm{mL}^{-1}$.

\section{Eosinophil peroxidase staining}

Eosinophils were visualised in conventional cryostat sections $(10 \mu \mathrm{m})$ using enzyme histochemical staining of cyanideresistant EPO, as described previously [9]. Briefly, the specimens were rinsed thoroughly in PBS buffer, and incubated for $3 \mathrm{~min}$ at room temperature in PBS supplemented with 3.3diamino-benzidiene-tetrahydrochloride $\left(75 \mu \mathrm{g} \cdot 100 \mathrm{~mL}^{-1}\right)$, $\mathrm{H}_{2} \mathrm{O}_{2}\left(0.3 \mathrm{~mL} \cdot 100 \mathrm{~mL}^{-1}\right)$ and $\mathrm{NaCN}\left(50 \mathrm{mg} \cdot 100 \mathrm{~mL}^{-1}\right)$. Then, the samples were subsequently rinsed in water, counterstained with Harris haematoxylin, mounted in PERTEX (Histolab, Gothenburg, Sweden) and examined on a bright field microscope. The total number of eosinophils was counted in two sections from each biopsy. All quantifications were carried out in a blinded fashion.

\section{Immunohistochemistry}

Cryo sections $(10 \mu \mathrm{m}$ thick) were rinsed in Tris buffered saline (TBS; pH 7.6), and nonspecific binding sites were blocked with normal rabbit serum (Dako; dilution 1:10 in TBS) for $10 \mathrm{~min}$. Sections were incubated with primary monoclonal antibodies overnight at $4{ }^{\circ} \mathrm{C}$. The monoclonal antibody EG2 (Pharmacia Diagnostics; dilution 1:80), which, in formaldehyde-fixed tissues, recognises both "resting" and secreted forms of ECP [15], was used to detect intra- and extracellular ECP. After incubation with the primary antibodies, specimens were rinsed in TBS and incubated 
with a secondary antibody (rabbit anti-mouse Texas Red; Jackson, MS, USA; dilution 1:80 in 20\% normal human serum) for $30 \mathrm{~min}$. After washing-in, TBS sections were incubated with a fluorescein isothiocyanate (FITC) solution for $10 \mathrm{~min}$ at room temperature (FITC molecules have high affinity for the cationic proteins in eosinophil granules [16], and, in formaldehyde-treated tissues, can be used as a general staining of tissue eosinophils). Finally, the sections were rinsed, mounted in PBS:glycerine (1:3) and examined by epifluorescence illumination.

\section{Transmission electron microscopy}

After fixation, the biopsies were rinsed in buffer and postfixed in $1 \%$ osmium tetroxide for $1 \mathrm{~h}$ at room temperature. After which, they were dehydrated in graded acetone solutions and embedded in Polarbed 812 (Poly Science, Niles, IL, USA). Using an ultratome (Ultratome Nova, Leica, Germany), 1- $\mu \mathrm{m}$ plastic sections were cut and stained with toluidine blue. In order to avoid mechanically induced artefacts, the toluidine blue-stained sections were used to select tissue areas with a well-preserved morphology for further electron microscopy investigation. Thus, areas with evident mechanical distortions, e.g. abnormally stretched and ruptured tissues, were excluded from further analysis. Importantly, during this selection, which was carried out in a blinded fashion, the investigator could not distinguish the eosinophils. From the selected well-preserved areas, ultrathin sections $(90 \mathrm{~nm})$ were cut and placed on a 200-mesh, thin-bar, copper grid and contrasted by staining in uranyl acetate $(4 \%$ in $\mathrm{ddH}_{2} \mathrm{O}$ for $30 \mathrm{~min}$ at $\left.40^{\circ} \mathrm{C}\right)$ and with lead citrate $(0.5 \%$ in $1 \mathrm{M} \mathrm{NaOH}$ for $3 \mathrm{~min}$ at room temperature). The ultrastructural analysis was carried out using a Philips CM10 TEM (Philips, Eindhoven, The Netherlands).

\section{Ultrastructural analysis of eosinophils}

Eosinophils in the tissue were identified by their characteristic ultrastructural morphology, as described elsewhere [17]. The numbers of biopsies that contained sufficient numbers of eosinophils, and had a well-preserved morphology, i.e. no signs of mechanical artifacts, were at the pre- and postseasonal observations seven (March 8, 2000) and eight (May $9,2000)$, respectively. In these biopsies, each individual eosinophil was carefully analysed at 4,000-12,000× magnification.

Modes of degranulation or death were identified and quantified according to the following criteria. 1) Piecemeal degranulation (PMD) and quantification of PMD: intact cells displaying characteristic changes of specific granules residing within the cytoplasm, i.e. occurrence of partly empty intracellular granules with no signs of granule extrusion. In all individual eosinophils, the total number of granules was counted. Next, each specific granule was evaluated and classified as either an intact granule (with no signs of degranulation, i.e. intact core and matrix) or activated (various structural changes due to $\mathrm{PMD}$, e.g. ragged loss of the electron-dense core material, loss or coarsening of the granular matrix, or more or fewer empty granules). The extent of PMD for each individual eosinophil was calculated, defined as the percentage of activated granules and referred to as the degranulation index for that cell [10, 17]. 2) Eosinophil cytolysis (ECL): presence of chromatolysis, loss of plasma membrane integrity and partly dissolved cytoplasm [18, 19]. The extent of ECL was expressed as the percentage of total tissue eosinophils. 3) Eosinophil exocytosis: morphological signs of extrusion of whole membrane-free specific granules whose membranes have fused with the cell membrane [17, 20]. 4) Apoptotic eosinophils: presence of electron-dense (i.e. black), condensed chromatin, preserved plasma membrane and nondilated organelles [17, 21, 22].

\section{Statistics}

Differences in nasal symptoms, lavage fluid levels of ECP and $\alpha_{2}$-macroglobulin, and tissue eosinophil numbers were examined using the Friedman test (paired comparisons). If statistical significance emerged, further analyses were performed using the Wilcoxon signed rank test. Differences in tissue PMD indices were examined using the Mann-Whitney U-test (nonpaired comparisons). Correlations between lavage fluid levels of ECP and tissue eosinophil numbers, respectively, and tissue PMD indices were examined using the Spearman rank correlation test. Similarly, the Spearman rank correlation test was used for analyses of correlations between eosinophil indices and symptoms. Statistical p-values of $<0.05$ were considered significant. Data are presented as mean \pm SEM.

\section{Results}

\section{Seasonal symptoms}

The regional birch pollen counts were steadily increased during a period of 3 weeks in late April and early May. Accordingly, nasal symptoms recorded during this period were significantly increased. Compared with the first study week, i.e. March 18-24, the increase in total nasal symptoms reached statistical significance on study week $3(\mathrm{p}<0.05), 5$ $(\mathrm{p}<0.05), 6(\mathrm{p}<0.001)$, and $7(\mathrm{p}<0.001)$ (fig. 1).

\section{Lavage fluid levels of $\alpha_{2}$-macroglobulin and eosinophil cationic protein}

Nasal lavage fluid levels of $\alpha_{2}$-macroglobulin were elevated during the pollen season, and this increase reached statistical significance at the second $(\mathrm{p}<0.05)$, as well as the third $(\mathrm{p}<0.01)$ seasonal observation (c.f. before the season; fig. 2$)$. Similarly, levels of ECP were significantly increased at the

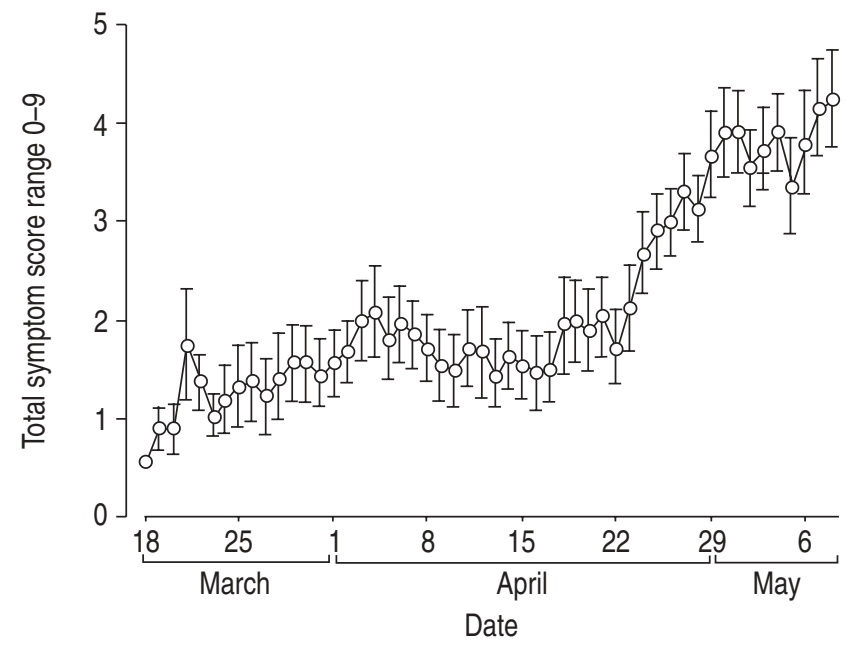

Fig. 1. - Nasal symptoms during the study period. Symptoms, which were recorded q.d., developed gradually during the pollen season. Data are presented as mean \pm SEM. 

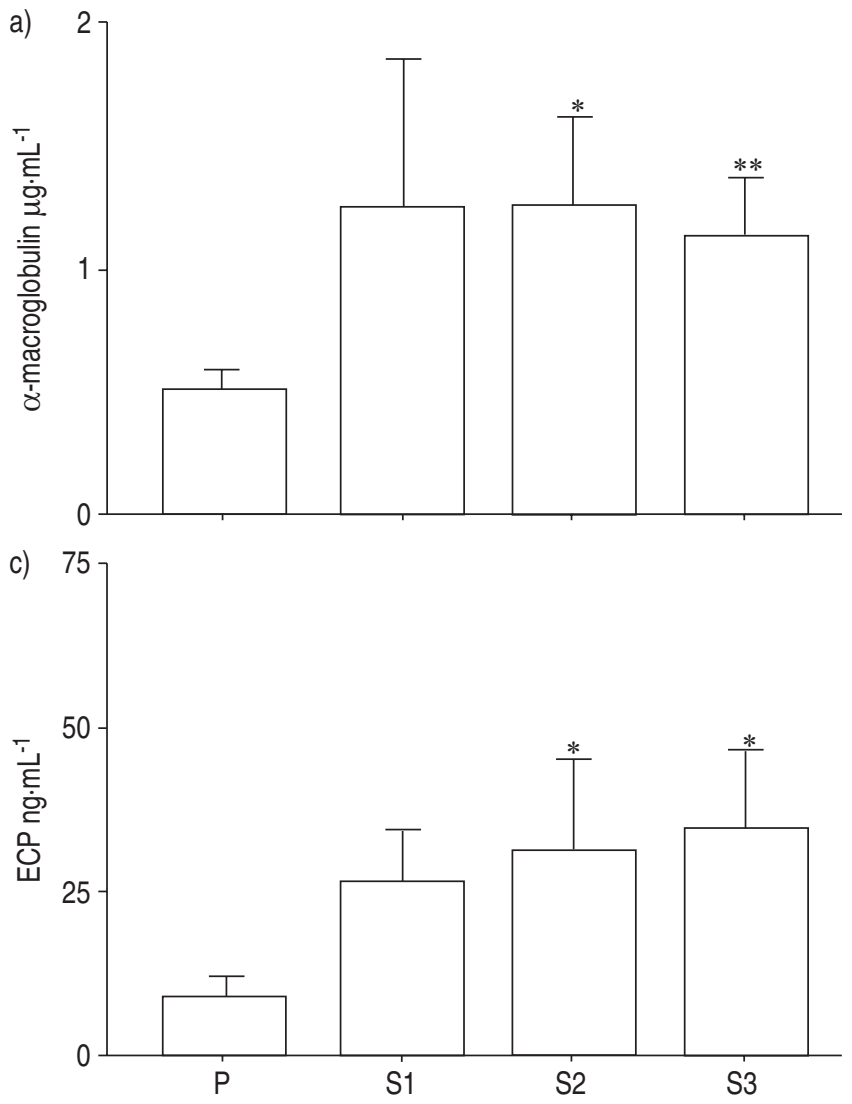

b)

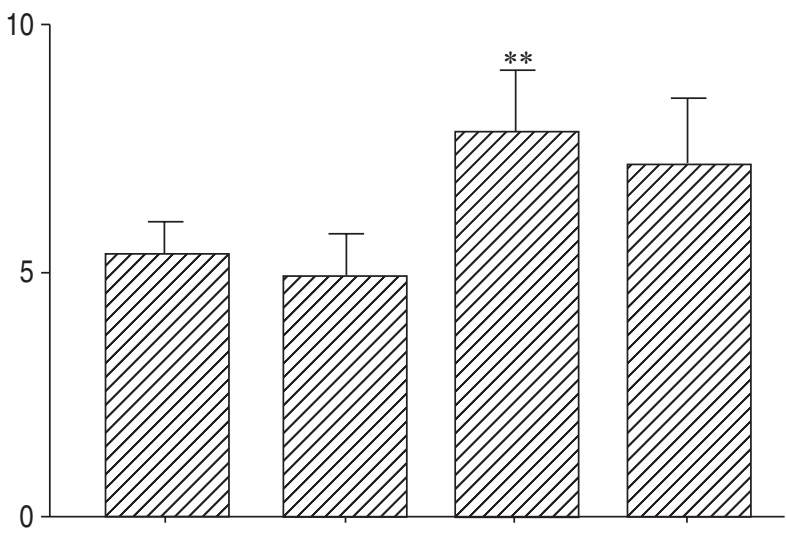

d)

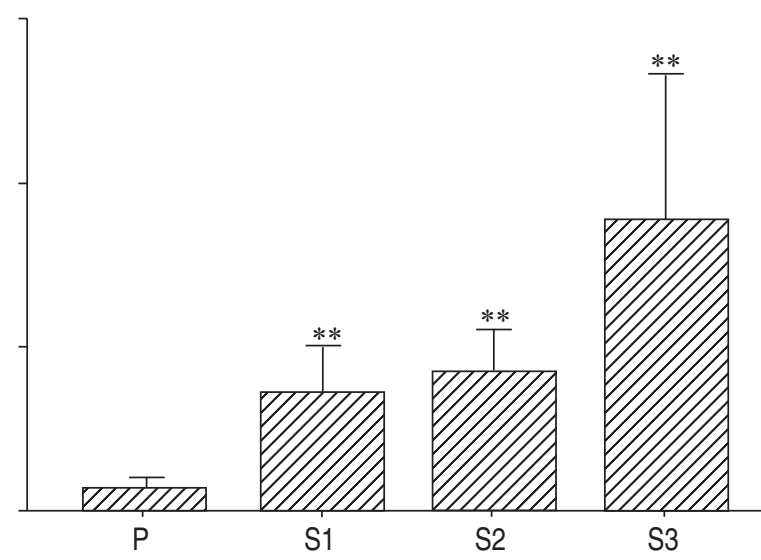

Fig. 2. - Nasal saline lavage fluid levels of $\alpha_{2}$-macroglobulin (a and b) and eosinophil catatonic protein (ECP; c and d) during the study period, obtained after saline $(\square)$ or histamine challenge $(\mathbb{Z})$. Data are presented as mean \pm SEM. P: pre-seasonal; $\mathrm{S}$ : seasonal. $*$ : p $<0.05$; $* *$ : p $<0.01$.

second $(\mathrm{p}<0.05)$ and third $(\mathrm{p}<0.05)$ seasonal observation (before the season; fig. 2).

Histamine produced significant plasma exudation, i.e. increased nasal lavage fluid levels of $\alpha_{2}$-macroglobulin, before as well as during the pollen season $(\mathrm{p}<0.001$; c.f. diluent challenge; fig. 2). At the second seasonal observation, the exudative responsiveness to histamine was increased $(\mathrm{p}<0.01$; c.f. before the season). Also, throughout the seasonal observations, levels of ECP were further increased in the histamine lavage fluids $(\mathrm{p}<0.01 ;$ c.f. before the season; fig. 2$)$. Nasal lavage fluid levels of $\alpha_{2}$-macroglobulin correlated (correlation: $\rho)$ with ECP levels in saline $(\rho=0.825, p<0.0001)$ and histamine lavage fluids $(\rho=0.389, \mathrm{p}<0.01)$.

\section{Tissue eosinophilia}

Numbers and distribution of tissue eosinophils were assessed using EPO-stained cryosections. Eosinophils were present in $56 \%$ of the biopsies obtained before season. At seasonal allergen exposure, $82 \%$ of the biopsies contained eosinophils, and the numbers of eosinophils were significantly increased compared with pre-seasonal values (fig. 3a). In both groups, eosinophils were mainly distributed in the lamina propria tissue, just beneath the basement membrane of the surface epithelium.

\section{Eosinophil degranulation}

Piecemeal degranulation. Both before and during the pollen season, signs of eosinophil degranulation could be detected in all examined tissue regions (figs 3b, 4a, 5 and 6). However, areas with extensive or completely degranulated eosinophils were present only during the pollen season (figs $4 \mathrm{~b}, \mathrm{c}, \mathrm{h}, \mathrm{i}$ and 5). Among the pre-seasonal tissue eosinophils, an average of $37 \pm 2.7 \%$ of the granules were altered as a result of PMD (fig. 3b). The granule alterations during PMD were characterised by mild-to-moderate loss of either core or matrix, or moderate-to-complete loss of both compartments (fig. $4 \mathrm{~d}-\mathrm{g}$ ).

In association with seasonal pollen exposure, the extent of degranulation was increased to mean \pm SD $87 \pm 1.8 \%$ altered granules $(p<0.01)$, and, in many eosinophils, every granule displayed signs of protein loss. Thus, eosinophils exhibiting signs of severe-to-complete loss of granule content were exclusively observed during the pollen season. The seasonal tissue eosinophils involved in extensive PMD also contained increased numbers of small secretory granules compared with the eosinophils observed in the tissue prior to the pollen season. There was a significant correlation between the PMD index and levels of ECP in the histamine lavage fluids $(\rho=0.629, p<0.05)$, as well as between tissue eosinophil numbers and levels of ECP in these lavages $(\rho=0.637$, $\mathrm{p}<0.05$ ). Otherwise, the lavage fluid levels of ECP exhibited no correlation with eosinophil features examined in this study (table 1).

In general, the epithelial layer was well preserved both before and during the pollen season. However, in few scattered areas of biopsies obtained during the season, signs of patchy epithelial damage and repair were found. Epithelial changes in these regions included a reduced epithelial thickness and occurrence of epithelial metaplasia with poorly differentiated epithelial cells [23]. Interestingly, eosinophils 

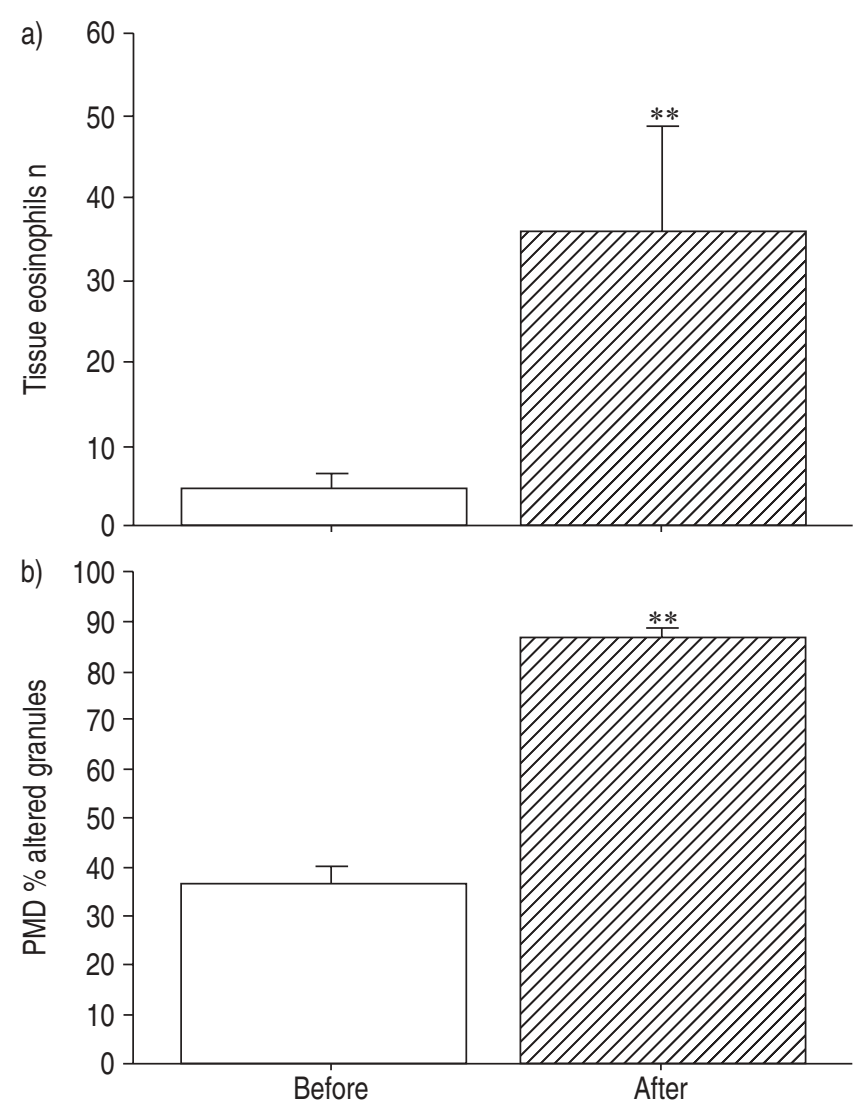

Fig. 3.-a) Numbers of tissue eosinophils and b) extent of piecemeal degranulation (PMD) in biopsies obtained before ( $\square$ ) and after (ש) the pollen season. Prior to the season, few eosinophil peroxidepositive tissue eosinophils were observed together with a marginal degranulation. In association with seasonal allergen exposure, both the tissue numbers of eosinophils and the mean degranulation level increased significantly. Data are presented as mean \pm SEM. ${ }^{* *}: \mathrm{p}<0.01$.

involved in extensive PMD and ECL abounded in these areas (fig. 4h, i).

Extracellular depositions of eosinophil cationic protein. Extracellular tissue depositions of eosinophil granule proteins were assessed in cryo sections by immunohistochemical staining for ECP. Prior to the pollen season, no or weak extracellular immunoreactivity was detected in tissue regions closely surrounding the eosinophils (fig. 6a). In contrast, during the allergen season, areas of weak-to-moderate ECP staining were complemented with regions displaying intense extracellular staining of ECP (fig. 6b). The intensively stained areas occasionally also occurred in tissue areas where only few eosinophils were detected.

Eosinophil cytolysis, excocytosis and apoptosis. Eosinophil cytolysis was rarely observed among eosinophils present in biopsies obtained prior to allergen exposure. During the pollen season, there was a clear, although not statistically significant, trend towards an increased proportion of cytolytic eosinophils, characterised by ruptured cell membrane, chromatolysis, and extracellular release of granules with retained membrane area (inset of fig. $4 \mathrm{~h}, \mathrm{i}$ ); $23.1 \pm 5.6 \%$ of the total tissue eosinophils displayed ultrastructural signs of cytolysis during the pollen season compared with $5.5 \pm 5.4 \%$ prior to the season. Using the current detailed TEM analysis, no eosinophils displaying classical ultrastructural signs of apoptosis or exocytosis were detected prior to or during the seasonal allergen exposure.

\section{Symptoms and eosinophil indices}

The present study material allows for explorations of potential correlations between symptoms of allergic rhinitis and different indices of eosinophil activity. Accordingly, such symptoms correlated with the levels of ECP in the saline lavages $(\rho=0.22, p<0.05)$, as well as in the histamine lavages $(\rho=0.52, p<0.0001)$. Also, these symptoms correlated with eosinophil numbers $(\rho=0.59, p<0.001)$ and the PMD index $(\rho=0.73, p<0.01)$.

\section{Discussion}

Through detailed ultrastructural analysis, for the first time, the present study demonstrates the degranulation status of tissue eosinophils prior to and during symptomatic seasonal allergic rhinitis. The current data show that the eosinophils are already present and are of a "mild" degranulating phenotype during nonsymptomatic baseline conditions in this disease. Moreover, during symptom-inducing seasonal allergen exposure not only eosinophil numbers but also the degranulation status are dramatically increased to an extent where nearly every eosinophil granule exhibits signs of extensive protein loss. This ultrastructural picture is complemented by increased occurrence of tissue areas with intense immunoreactivity for ECP and an increased mucosal output of ECP. Hence, during active allergic rhinitis, it appears that a combination of increased accumulation of tissue eosinophils and an extensive degranulation produces high levels of extracellular depositions of eosinophil granule products in the target tissue.

The only available method that can identify and quantify different modes of degranulation is ultrastructural analysis by TEM, a technique that reveals in detail the degranulation status of individual eosinophils [17, 18]. Based on such detailed analyses, the current authors have developed the present method of quantification of the major modes of degranulation in vivo (i.e. PMD and eosinophil cytolysis) [10]. With regards to PMD, the calculated PMD index in this study is defined as the percentage of granules displaying morphological signs of protein release. Notably, PMD observed during allergen exposure was associated with the appearance of granules with a more marked loss of core and matrix compartments than that observed prior to the season. Hence, it appears that, in the present study, the actual increase in protein release during the pollen season may even be greater than indicated by the PMD index analysis. It is suggested that the present seasonal increase in PMD (approximately threefold), together with the seven-fold increase in eosinophil numbers, resulted in the dramatically increased tissue deposition of eosinophil products observed during the pollen season.

Previous biopsy studies examining patients with seasonal allergic rhinitis demonstrate that, even during off-seasonal conditions, the number of nasal tissue eosinophils may be elevated compared with healthy, nonatopic individuals [24]. The current study confirms the occurrence of a moderate baseline eosinophilia and further demonstrates that these eosinophils are often of a degranulating phenotype (the degranulation was less pronounced than in symptomatic patients during the season). However, several facts suggest that the off-season eosinophil features do represent true degranulation compared with a proper baseline, such as that represented by circulating blood eosinophils. Thus, using the present quantitative electron microscope approach, it has recently been demonstrated that blood eosinophils examined both before and during the pollen season lack the type of granule alterations observed in the present study [25]. Also, 

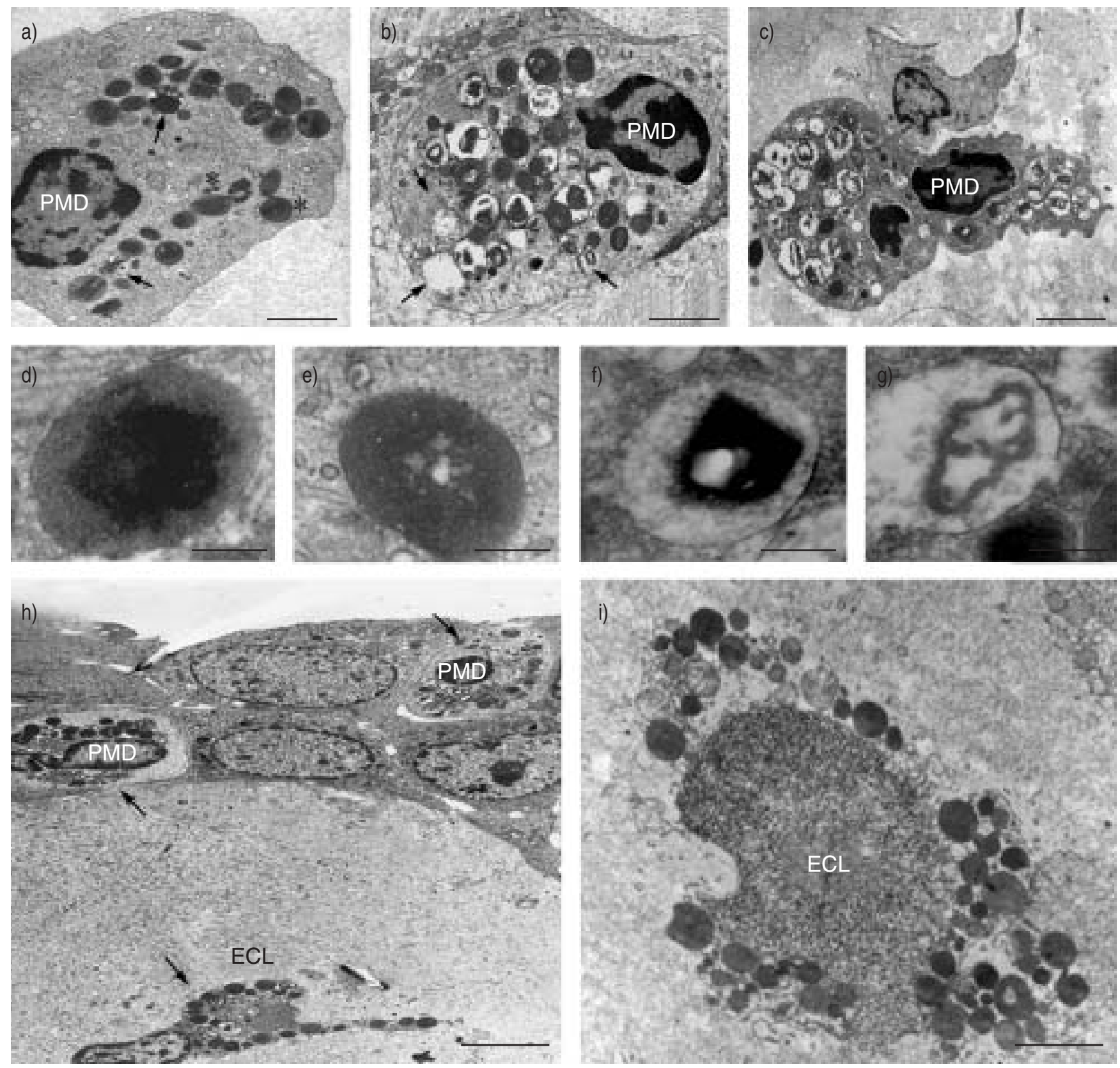

Fig. 4. - Transmission electron micrographs demonstrating representative images of nasal tissue eosinophils before (a) and during (b, c, h, and i) the pollen season. The typical tissue eosinophil that is present before the season has abundant normal granules $(*)$, together with scattered granules displaying structural signs of piecemeal degranulation (PMD; arrows in part a). During the pollen season, the majority of the granules are structurally altered due to PMD (arrows in part b). c) Eosinophils with virtually all granules involved in extensive protein release were exclusively observed during the pollen season, when eosinophils undergoing cytolysis (ECL) were also observed (h, i). The typical granule changes during PMD included selective loss of electron density in the granule core (e), more or less selective loss of matrix material (f), or moderate-to-severe loss of both core and matrix (g). In scattered patchy areas of epithelial damage and repair, activated eosinophils represented the major infiltrating cell type (h, i). Scale bars $=2 \mu \mathrm{m}$ (a and b), $3.5 \mu \mathrm{m}(\mathrm{c}), 350 \mathrm{~nm}(\mathrm{~d}-\mathrm{g}), 5 \mu \mathrm{m}(\mathrm{h})$, and $1 \mu \mathrm{m}(\mathrm{i})$.

the occurrence of abundant small vesicles in the cytoplasm, as observed before the season in the present study, is known to be associated with an ongoing degranulation [18]. Hence, it appears that, even before symptoms develop in seasonal rhinitis, some degranulation of eosinophils occurs after they have reached the airway tissue.

In light of the present debate on the pathogenic role of eosinophils [7, 26, 27], it is suggested that demonstrations of the presence of eosinophils must probably be complemented with data on degranulation, in order to indicate a possibility of involvement of eosinophils in disease processes. In agreement, the present eosinophil PMD index did not correlate with eosinophil numbers in the nasal mucosa. Also, degranulation cannot be taken for granted just because the eosinophilic tissue is inflamed. Thus, it was recently demonstrated that different eosinophilic conditions are characterised by a marked heterogeneity in degranulation levels [8]. For example, the colonic mucosa during active ulcerative colitis or Crohn's disease is subjected to eosinophilia and severe inflammation, yet the tissue eosinophils may show little signs of degranulation. Tissue eosinophils with little pronounced degranulation might also be found in asthma and nasal polyposis, two conditions that further appear to be characterised by large differences in degranulation 


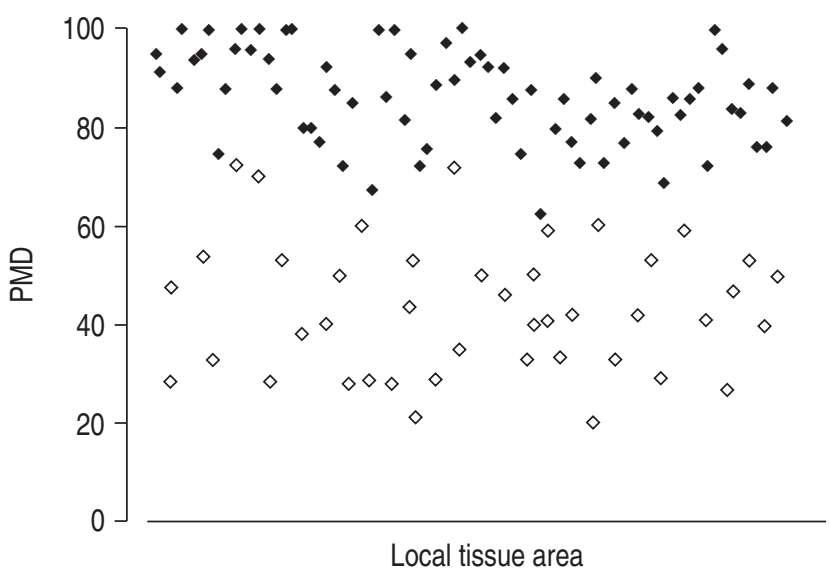

Fig. 5.-Scattergram exemplifying the piecemeal degranulation (PMD) levels in randomly plotted local tissue areas, examined before $(\diamond)$ and during $(\diamond)$ the allergen season. Each data point represents the mean degranulation in each examined tissue area. Although there is a clear difference between the two study groups, signs of degranulation were present in all examined regions.

between individuals. The fact that eosinophils display heterogeneity in human tissues may not be surprising. For example, apart from being defence effector cells (i.e. release of direct cytotoxic molecules), eosinophils may also act as immunomodulatory and antigen-presenting cells [28-31]. Furthermore, eosinophils can, through their ability to release growth factors, such as transforming growth factor- $\beta$, promote tissue remodelling and repair [32, 33]. In this context, it is of note that anti-IL-5 therapy, although not significantly improving symptoms in asthma, appears to have an effect on airway remodelling parameters [34]. The previously mentioned heterogeneity underscores a problem of inconsistencies in studies on the role of eosinophils and in evaluating antieosinophilic drugs. Importantly, the present findings, together with previous data on the presence and degranulation status of eosinophils in the diseased tissue, suggest that allergic rhinitis may exhibit an exceptional consistency as regards an extensive eosinophil degranulation $[35,36]$.

The present study has confirmed that increased nasal lavage fluid levels of $\alpha_{2}$-macroglobulin and ECP, reflecting plasma exudation and increased eosinophil activity, respectively, characterise allergic rhinitis at seasonal allergen exposure [37]. In further agreement with previous observations, there was also a significant correlation between the luminal levels of these two markers. The co-appearance of $\alpha_{2}$-macroglobulin and ECP on the mucosal surface support the current hypothesis that the plasma exudation process transports free tissue molecules, such as ECP, into the airway lumen [11, 38]. Thus, during the plasma extravasation response, there is an unidirectional (tissue to lumen) bulk flow of plasma containing multiple binding proteins that contribute to an efficient rinsing of the extracellular tissue spaces of the airway mucosa $[11,38]$. The capacity of plasma extravasation to move ECP into the nasal cavity is also suggested by the present observation that seasonal levels of ECP recorded at histamine challenge were high, despite the fact that these lavages followed directly after saline lavages, which had probably removed any accumulated luminal ECP. Thus, luminal levels of ECP, recorded after the combination of a saline lavage followed by a histamine challenge/lavage, may reflect tissue levels of free ECP. Indeed, in the present study, it was only the lavage fluid levels of ECP recorded at histamine challenge (before and during the pollen season taken together) that correlated significantly to the PMD index. Intriguingly, one potential implication of using combined histamine
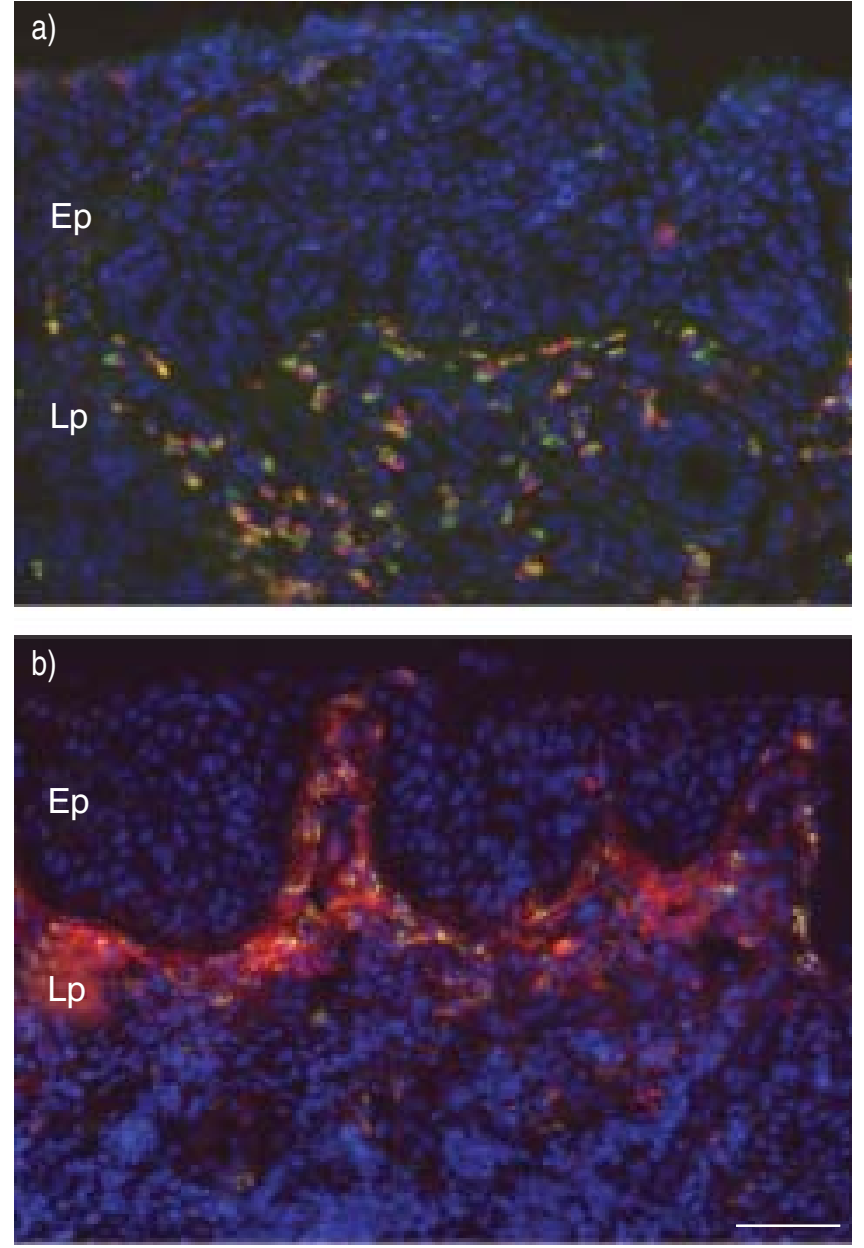

Fig. 6.-Fluorescence micrographs of tissue distribution of eosinophil cationic protein (ECP) in a mucosal area examined before (a) and during (b) the pollen season. The distribution of ECP was visualised by indirect immunofluorescence using Texas Red as a detection fluorochrome (red staining). The eosinophils were also identified using the high binding affinity of the fluorochrome fluorescein isothiocyanate to eosinophil granules (green staining). Hoechst 33342 was used to stain the cell nuclei (blue staining). The ECP immunoreactivity in biopsies examined prior to the season was mainly distributed within eosinophils (a). b) The tissue region is characterised by an extensive extracellular ECP immunoreactivity in the lamina propria tissue (Lp) just beneath the surface epithelium (Ep). Scale bar (for $\mathrm{a}$ and $\mathrm{b}$ ) $=80 \mu \mathrm{m}$.

challenges/lavages would be to generate luminal samples that, better than saline lavages alone, reflect the extracellular molecular milieu in the airway mucosa. Tentatively, ECP in such lavages may also reflect better the eosinophil activity than tissue eosinophil numbers.

In summary, the present study originally demonstrates that moderately degranulated eosinophils are already present in the nasal mucosa during nonsymptomatic baseline conditions in seasonal allergic rhinitis. At natural allergen exposure, the degranulation activity of individual eosinophils is markedly

Table 1.-Correlations ( $\rho)$ between different indices of eosinophil presence/activity

Eosinophils $\rho \quad$ Saline ECP $\rho$ Histamine ECP $\rho$

\begin{tabular}{llll}
\hline PMD index & 0.256 & 0.479 & $0.629^{*}$ \\
Eosinophils & & 0.122 & $0.637^{*}$
\end{tabular}

ECP: eosinophil cationic protein; PMD: piecemeal degranulation. *: $\mathrm{p}<0.05$. 
increased, which, in combination with elevated numbers of tissue eosinophils, dramatically increases the amount of granule proteins released into the target tissue. In addition, the present study highlights histamine-induced acute plasma extravasation and concomitant luminal lavage as a potentially useful approach to enrich the lavage content of relevant tissue mediators, such as eosinophil cationic protein. Finally, it is suggested that seasonal allergic rhinitis may be a particularly suitable condition for studies of the potential pathogenic roles of eosinophils and for early testing anti-eosinophilic drugs.

\section{References}

1. Reed CE. The importance of eosinophils in the immunology of asthma and allergic disease. Ann Allergy 1994; 72: 376-380.

2. Rothenberg ME. Eosinophilia. N Engl J Med 1998; 338: 1592-1600.

3. Filley WV, Holley KE, Kephart GM, Gleich GJ. Identification by immunofluorescence of eosinophil granule major basic protein in lung tissues of patients with bronchial asthma. Lancet 1982; 2: 11-16.

4. Busse WW, Sedgwick JB, Jarjour NN, Calhoun WJ. Eosinophils and basophils in allergic airway inflammation. J Allergy Clin Immunol 1994; 94: 1250-1254.

5. Leckie MJ, ten Brinke A, Khan J, et al. Effects of an interleukin-5 blocking monoclonal antibody on eosinophils, airway hyper-responsiveness, and the late asthmatic response. Lancet 2000; 356: 2144-2148.

6. Kips JC, O'Connor BJ, Langley SJ, et al. Effect of SCH55700, a humanized anti-human interleukin-5 antibody, in severe persistent asthma: a pilot study. Am J Respir Crit Care Med 2003; 167: 1655-1659.

7. Lacy P, Weller PF, Moqbel R. A report from the International Eosinophil Society: eosinophils in a tug of war. J Allergy Clin Immunol 2001; 108: 895-900.

8. Erjefält JS, Greiff L, Andersson M, Adelroth E, Jeffery PK, Persson CG. Degranulation patterns of eosinophil granulocytes as determinants of eosinophil driven disease. Thorax 2001; 56: 341-344.

9. Erjefält JS, Greiff L, Andersson M, et al. Allergen-induced eosinophil cytolysis is a primary mechanism for granule protein release in human upper airways. Am J Respir Crit Care Med 1999; 160: 304-312.

10. Erjefält JS, Andersson M, Greiff L, et al. Cytolysis and piecemeal degranulation as distinct modes of activation of airway mucosal eosinophils. J Allergy Clin Immunol 1998; 102: 286-294.

11. Greiff L, Andersson M, Erjefält JS, Svensson C, Persson CG. Loss of size-selectivity at histamine-induced exudation of plasma proteins in atopic nasal airways. Clin Physiol Funct Imaging 2002; 22: 28-31.

12. Greiff L, Pipkorn U, Alkner U, Persson CG. The "nasal pool" device applies controlled concentrations of solutes on human nasal airway mucosa and samples its surface exudations/secretions. Clin Exp Allergy 1990; 20: 253-259.

13. Svensson C, Grönneberg R, Andersson M, et al. Allergen challenge-induced entry of alpha 2-macroglobulin and tryptase into human nasal and bronchial airways. J Allergy Clin Immunol 1995; 96: 239-246.

14. Greiff L, Petersen H, Mattsson E, et al. Mucosal output of eotaxin in allergic rhinitis and its attenuation by topical glucocorticosteroid treatment. Clin Exp Allergy 2001; 31: 1321-1327.

15. Jahnsen F, Halstensen TS, Brandtzaeg P. Immunostaining with monoclonal antibodies to eosinophil cationic protein (EG1 and EG2) does not distinguish between resting and activated eosinophils in formalin-fixed tissue specimens. $A d v$ Exp Med Biol 1995; 371A: 283-286.

16. Bedner E, Halicka HD, Cheng W, et al. High affinity binding of fluorescein isothiocyanate to eosinophils detected by laser scanning cytometry: a potential source of error in analysis of blood samples utilizing fluorescein-conjugated reagents in flow cytometry. Cytometry 1999; 36: 77-82.

17. Erjefält JS, Persson CG. New aspects of degranulation and fates of airway mucosal eosinophils. Am J Respir Crit Care Med 2000; 161: 2074-2085.

18. Weller PF, Dvorak AM. Human eosinophils: development, maturation, and functional morphology. In: Busse WW, Holgate ST, eds. Asthma and rhinitis. Boston, Blackwell, 1994; pp. 255-274.

19. Persson CG, Erjefält JS. Eosinophil lysis and free granules: an in vivo paradigm for cell activation and drug development. Trends Pharmacol Sci 1997; 18: 117-123.

20. Dvorak AM, Onderdonk AB, McLeod RS, et al. Ultrastructural identification of exocytosis of granules from human gut eosinophils in vivo. Int Arch Allergy Immunol 1993; 102: 33-45.

21. Dvorak AM. Images in clinical medicine. An apoptotic eosinophil. N Engl J Med 1999; 340: 437.

22. Majno G, Joris I. Apoptosis, oncosis, and necrosis. An overview of cell death. Am J Pathol 1995; 146: 3-15.

23. Erjefält JS, Persson CGA. Epithelial repair: breathtakingly quick and multipotentially pathogenic. Thorax 1997; 52: $1010-1012$.

24. Togias A, Naclerio RM, Proud D, et al. Studies on the allergic and nonallergic nasal inflammation. J Allergy Clin Immunol 1988; 81: 782-790.

25. Malm-Erjefält GMK, Greiff L, Andersson M, et al. Marginal ultrastructural signs of degranulation in circulating eosinophils and neutrophils from symptomatic patients with asthma and allergic rhinitis. Am J Respir Crit Care Med 2003; 167: 757.

26. $\mathrm{O}^{\prime}$ Byrne $\mathrm{PM}$, Inman MD, Parameswaran $\mathrm{K}$. The trials and tribulations of IL-5, eosinophils, and allergic asthma. J Allergy Clin Immunol 2001; 108: 503-508.

27. Giembycz MA. Are eosinophils out of asthma? Trends Mol Med 2001; 7: 52.

28. Weller PF, Lim K, Wan HC, et al. Role of the eosinophil in allergic reactions. Eur Respir J 1996; 9: Suppl. 22, 109s-115s.

29. Shi HZ, Humbles A, Gerard C, Jin Z, Weller PF. Lymph node trafficking and antigen presentation by endobronchial eosinophils. J Clin Invest 2000; 105: 945-953.

30. Giembycz MA, Lindsay MA. Pharmacology of the eosinophil. Pharmaco Rev 1999; 51: 213-340.

31. Persson-Dajotoy T, Andersson P, Bjartell A, Calafat J, Egesten A. Expression and production of the CXC chemokine growth-related oncogene-alpha by human eosinophils. J Immunol 2003; 170: 5309-5316.

32. Ohno I, Nitta Y, Yamauchi K, et al. Transforming growth factor beta 1 (TGF beta 1) gene expression by eosinophils in asthmatic airway inflammation. Am J Respir Cell Mol Biol 1996; 15: 404 409.

33. Erjefält JS, Sundler F, Persson CG. Eosinophils, neutrophils, and venular gaps in the airway mucosa at epithelial removalrestitution. Am J Respir Crit Care Med 1996; 153: 1666-1674.

34. Flood-Page P, Menzies-Gow A, Phipps S, et al. Anti-IL-5 treatment reduces deposition of ECM proteins in the bronchial subepithelial basement membrane of mild atopic asthmatics. J Clin Invest 2003; 112: 1029-1036.

35. Watanabe K, Hasegawa M, Saito Y, Takayama S. Eosinophilic leukocytes in nasal allergy: movement of enzymes. Clin Exp Allergy 1977; 7: 263-271.

36. Greiff L, Erjefält JS, Andersson M, Svensson C, Persson CG. Generation of clusters of free eosinophil granules (Cfegs) in seasonal allergic rhinitis. Allergy 1998; 53: 200-203.

37. Meyer P, Persson CG, Andersson M, et al. Alpha2macroglobulin and eosinophil cationic protein in the allergic airway mucosa in seasonal allergic rhinitis. Eur Respir $J$ 1999; 13: 633-637.

38. Persson CG, Erjefält JS, Greiff L, et al. Plasma-derived proteins in airway defence, disease and repair of epithelial injury. Eur Respir J 1998; 11: 958-970. 